\title{
Factors contributing to patient dumping in Taiwan
}

\author{
Herng-Ching Lin ${ }^{\mathrm{a}}$,*, Senyeong Kao ${ }^{\mathrm{b}}$, Chao-Hsiun Tang ${ }^{\mathrm{a}}$, \\ Ming-Chin Yang ${ }^{\mathrm{c}}$, Hong-Shen Lee ${ }^{\mathrm{d}}$ \\ ${ }^{a}$ School of Health Care Administration, Taipei Medical University, 250 Wu-Hsing St., Taipei 110, Taiwan \\ ${ }^{\mathrm{b}}$ National Defense Medical Center, School of Public Health, Taipei, Taiwan \\ ${ }^{c}$ Graduate Institute of Health Care Organization Administration, National Taiwan University, Taipei, Taiwan \\ ${ }^{\mathrm{d}}$ Department of Public Health, Chung Shan Medical University, Taichung, Taiwan
}

\begin{abstract}
Objective: Little research has been carried out to explore the issues surrounding patient dumping outside of the US. This study, therefore, uses a national research survey to examine the factors contributing to patient dumping within Taiwan.

Methods: A self-administered postal survey was undertaken to assess the prevalence of patient dumping in Taiwan, with the study subjects being superintendents of general hospitals. Data from the Bureau of Medical Affairs at the Department of Health in Taiwan were used in conjunction with the Taiwan National Health Insurance Research Database (NHIRD) to obtain estimates of factors potentially contributing to patient dumping. A multiple logistic regression analysis was performed to determine the relationships between the perceived extent of patient dumping occurring within the respondents' healthcare networks, as well as other factors, including the total number of hospitals, total number of hospital beds, the percentages of beds in public, for-profit and teaching hospitals (vis-à-vis all hospital beds), discharges, discharges covered under the case payment system, transferred inpatients, and the perceived degree of competition within each healthcare market.

Results: A total of 485 survey questionnaires were distributed, of which 251 were returned, giving a response rate of $51.75 \%$. The responses from $29.9 \%$ of the sample group indicated that the perceived extent of patient dumping occurring in their service area was 'serious' or 'very serious'. The regression analysis showed that after controlling for other factors, the superintendents' perceived extent of the patient dumping occurring within their healthcare networks was positively related to the total number of patients covered under the case payment system, the total number of discharged patients, the extent of healthcare market competition and the number of respondent's hospital beds.

Conclusions: We conclude from our findings that, under the National Health Insurance system, patient dumping is a widespread problem within Taiwan's healthcare industry.
\end{abstract}

(C) 2005 Elsevier Ireland Ltd. All rights reserved.

Keywords: Patient dumping; National Health Insurance; Market competition

\section{Introduction}

* Corresponding author. Tel.: +886 22736 1661x3613; fax: +886223789788.

E-mail address: henry11111@tmu.edu.tw (H.-C. Lin).
Studies in the US have revealed a sharp increase, from the 1980s onwards, in the number of patients being transferred between hospitals based purely 
upon economic considerations [1,2]. Such a phenomenon of patient transferals from treating hospitals to other healthcare providers on economic grounds was described by Schlesinger et al. as 'patient dumping' [3]. The Public Citizen's Health Research Group estimated that about 250,000 patients per year were now being transferred based upon economic considerations rather than a patient's need for medical care [4]. More precisely, the total number of US hospitals committing violations of patient dumping between April 1994 and April 1995 stood at 144 [5]; however, this climbed significantly in the subsequent year to 250 [1], and more than doubled again to 527 violating hospitals over the period from 1996 to 2000 [6]. Clearly, therefore, patient dumping has become a very widespread and serious problem across the US.

While studies documenting the increasing frequency of patient dumping in the US are plentiful, to our knowledge, little research has yet been undertaken on the issues relating to patient dumping in other countries. Although one study on 128 hospitals in Taiwan, undertaken by Lin et al. found that $83.8 \%$ of the superintendents sampled felt that there was a certain degree of patient dumping occurring within their service areas [7], their pilot study, which involved a survey of just 128 selected hospitals, examined only whether patient dumping actually occurred under the Taiwan National Health Insurance (NHI); they did not attempt to explore the factors contributing to such patient dumping.

Using a nationwide survey, the main purposes of this study are, therefore, to investigate the perceived prevalence of patient dumping by hospital superintendents, and to try to gain an understanding of the factors that potentially contribute to patient dumping under the Taiwan NHI. This study may help policymakers in Taiwan, as well as in other countries, to gain an understanding of the extent to which patient dumping can occur among hospitals under an NHI. The findings of this study may also shed some light on the factors that can potentially contribute to patient dumping, and may also help to increase awareness of the issue of patient dumping among healthcare professionals.

\section{Methods}

The subjects of this study were superintendents of general hospitals in Taiwan, which had been accredited, in 2003, either as medical centers, regional hospitals or district hospitals by the Taiwan Joint Commission on Hospital Accreditation. All hospital superintendents in Taiwan are also practicing physicians; thus, their opinions may well provide an accurate picture of patient dumping as it occurs in their own hospitals or healthcare market networks. The total study population, comprising of 485 general hospital superintendents, was made up of superintendents from 17 medical centers, 72 regional hospitals and 396 district hospitals. A selfadministered postal survey was carried out, comprising of a structured questionnaire, between 15 August and 5 November 2004 in order to assess the prevalence of patient dumping. During this survey period, two follow-up calls were made to non-respondents with the aim of encouraging their participation so as to further increase the response rate.

The survey questionnaire adopted for this study comprised of three parts (see the Appendix A). The development of the first part, concerning the prevalence of patient dumping as perceived by hospital superintendents, was based mainly upon a survey conducted by Schlesinger et al., and included four questions aimed at measuring such perceived prevalence [3]. Since the study subjects' perceptions of 'patient dumping' may be quite varied, the term is clearly defined, at the beginning of the questionnaire, as 'the transfer of patients from the treating hospital to other hospitals based solely upon economic grounds'.

The second part of the questionnaire was designed to provide an understanding of the superintendents' attitudes towards patient dumping, while the third part comprised of questions on the hospital background, such as hospital level, the healthcare network within which the hospital was located, the total number of hospital beds and hospital ownership (public, private not-for-profit [NFP] and private for-profit [FP]).

The overall healthcare market in Taiwan is classified by the Department of Health (DOH) into 17 healthcare networks based upon geographical human settlement locations. The hospital level classification refers to medical centers (minimum 500 beds), regional hospital (minimum 250 beds) and district hospital (minimum 20 beds).

Based upon previous studies, in this study the factors potentially contributing to patient dumping were classified into hospital ownership [4,8,9], teaching status [10], the degree of market competition [10], and the 
implementation of a prospective payment system (PPS) $[3,10,11]$. Data from the Bureau of Medical Affairs at the DOH in Taiwan were used to calculate the percentages of beds in public, FP and teaching hospitals (vis-à-vis the total number of beds in all hospitals) within the healthcare network.

With regard to market competition, we used the perception of the extent of market competition by the superintendents themselves. Data on total discharge numbers within each healthcare network were sourced from the National Health Insurance Research Database (NHIRD) for the year 2003, which was the most up-todate version available at the time of completion of this study, since the NHIRD for the year 2004 has not yet been released.

This study uses the 2003 NHIRD to calculate the total number of discharges, the number of hospitalized patients being transferred, and the number of patients covered under the case payment system (one type of PPS), within each healthcare network. Statistical analysis was conducted using the Statistical Package for the Social Sciences (SPSS 10.0 for Windows, 1997, SPSS, Chicago, IL).

The $t$-test analyses were used to compare the superintendents' perceived extent of patient dumping occurring within their healthcare network with the total number of hospitals, total number of hospital beds, the percentages of beds in public, FP and teaching hospitals (vis-à-vis the total number of hospital beds), total discharges, discharges covered under the case payment system and the perceived degree of competition within each healthcare market. The perceived extent of patient dumping was treated as a dichotomous variable.

Those participants who answered 'very serious' and 'serious' to the question of estimating the perceived extent of patient dumping were recorded as 'serious' and those who answered 'average', 'not serious' and 'not at all' were recorded as 'not serious'. Thereafter, a multiple logistic regression analysis was performed in order to examine the relationship between the superintendents' perceived extent of patient dumping within their service areas and the factors, which potentially contribute to such patient dumping.

The independent variables in the regression model, which included the respondent's hospital characteristics and the factors, which potentially contribute to patient dumping, were selected on the basis of whether they displayed any significant association with the superintendents' perceived extent of patient dumping in the previous $t$-test analyses. All of the regression coefficients within the model were taken as significant at the $p<0.05$ level.

\section{Results}

Of the total of 485 questionnaires distributed, 251 were returned, giving an overall response rate of $51.75 \%$. The demographic characteristics of all of the sampled hospitals were similar to those of all general hospitals accredited by the Taiwan Joint Commission on Hospital Accreditation in 2003, in terms of hospital level $(p=0.199)$, location, teaching status $(p=0.157)$ and ownership ( $p=0.199)$ (Table 1).

Details of the respondents' perceived prevalence of patient dumping within their respective healthcare networks are provided in Table 2, which shows that $5.2 \%$ of the respondents felt that the extent of patient dumping occurring within their service areas was 'very serious', $24.7 \%$ felt it was 'serious', $31.1 \%$ responded with an 'average' assessment, $17.9 \%$ felt it was 'not serious', $5.2 \%$ responded 'not at all' and $15.9 \%$ provided a 'do not know' response.

A total of 61 of the 251 respondents $(24.3 \%)$ were unable to answer the question on the perceived percentage of hospitals within their service areas practicing patient dumping. Of those respondents who did attempt to answer this question $(n=190)$, the mean perceived percentage of hospitals practicing patient dumping was $13.47 \%$ with a standard deviation of $16.63 \%$.

Of all the emergency patients received by hospitals, the perceived percentage of patients, which had been dumped from other hospitals, ranged from 0 to $50 \%$, with a mean of $5.91 \%$, while the mean percentage of inpatients received into hospitals having been transferred from other hospitals, was $5.62 \%$. There were no significant differences between hospital level and the perceived percentage of hospitals engaging in patient dumping ( $p=0.266$ ), the percentage of all emergency patients received by transfer from other hospitals $(p=0.127)$, and the percentage of inpatients received by transfer from other hospitals $(p=0.150)$ (not shown in table).

Table 3 summarizes the overall attitudes of superintendents towards patient dumping, with the majority of respondents $(40.2 \%)$ feeling that patient dumping 
Table 1

Characteristics of sampled hospitals ${ }^{\mathrm{a}}$

\begin{tabular}{|c|c|c|c|}
\hline Variable & Respondents' total no. (\%) & Population total no. (\%) & $p$-Value ${ }^{\mathrm{b}}$ \\
\hline Hospital level & & & 0.199 \\
\hline Medical center & $14(5.6)$ & $17(3.5)$ & \\
\hline Regional hospital & $42(16.7)$ & $72(14.8)$ & \\
\hline District hospital & 195 (78.6) & $396(81.7)$ & \\
\hline Healthcare market network in which the hospital is located & & & 0.168 \\
\hline Keelung & $5(2.0)$ & $7(1.4)$ & \\
\hline Taipei & $56(22.3)$ & $82(16.9)$ & \\
\hline Taoyuan & $20(8.0)$ & $27(5.6)$ & \\
\hline Hsinchu & $13(5.2)$ & $17(3.5)$ & \\
\hline Miaoli & $2(0.8)$ & $15(3.1)$ & \\
\hline Taichung & $27(10.8)$ & $56(11.5)$ & \\
\hline Changhua & $16(6.4)$ & $36(7.4)$ & \\
\hline Nantou & $4(1.6)$ & $11(2.3)$ & \\
\hline Yunlin & $7(2.8)$ & $21(4.3)$ & \\
\hline Chiayi & $10(4.0)$ & $20(4.1)$ & \\
\hline Tainan & $18(7.2)$ & $39(8.0)$ & \\
\hline Kaohsiung & $42(16.7)$ & $98(20.2)$ & \\
\hline Pingtung & $15(6.0)$ & $29(6.0)$ & \\
\hline Taitung & $2(0.8)$ & $8(0.2)$ & \\
\hline Hualien & $6(2.4)$ & $8(0.2)$ & \\
\hline Ilan & $6(2.4)$ & $9(0.2)$ & \\
\hline Penghu & $2(0.8)$ & $2(0.4)$ & \\
\hline Hospital ownership & & & 0.199 \\
\hline Public & $61(24.3)$ & $70(14.4)$ & \\
\hline Private not-for-profit & $33(13.1)$ & $66(13.6)$ & \\
\hline Private for-profit & $157(62.5)$ & $349(72.0)$ & \\
\hline Teaching status & & & 0.157 \\
\hline Yes & 87 (35.4) & $131(27.0)$ & \\
\hline No & $159(64.6)$ & $354(73.0)$ & \\
\hline
\end{tabular}

a Total sample number $=251$.

b The $p$-values, which are calculated by Chi-square tests, showed no significant difference between respondents and population in terms of hospital level, distribution of healthcare market network where the hospital was located, ownership or teaching status.

brought about negative financial impacts on their hospital. With regard to the effects on patient dumping stemming from the case payment and global budget systems, $48.3 \%$ of all respondents 'agreed' or 'strongly agreed' that the implementation of the case payment system had escalated the incidence of patient dumping, and $84.9 \%$ also 'agreed' or 'strongly agreed' that the implementation of the global budget system had resulted in growth in the incidence of patient dumping. Furthermore, $66.5 \%$ of the respondents also 'agreed' or 'strongly agreed' that patient dumping had led to higher mortality rates and was associated with the increased consumption of medical resources.

Table 4 presents the results of the $t$-test analyses of the relationships between the superintendents' per- ceived extent of patient dumping occurring within their healthcare networks and the factors potentially contributing to this phenomenon. The analyses show a significant relationship between the superintendents' perceived occurrence of patient dumping and the number of patients covered by the case payment system $(p<0.001)$, the number of hospitals $(p=0.001)$, the total number of discharged patients $(p<0.001)$, the total number of hospital beds $(p<0.001)$, the total number of hospitalized patients transferred to other hospitals $(p<0.001)$ and the percentage of the number of beds in teaching hospitals (vis-à-vis the total number of beds) $(p<0.001)$.

Table 5 presents the results of the logistic regression analysis for the adjusted relationship between the 
Table 2

Perceived prevalence of patient dumping in respective healthcare networks ${ }^{\mathrm{a}}$

\begin{tabular}{|c|c|c|c|c|c|}
\hline Variable & Total no. $(\%)$ & Mean & S.D. & Maximum & Minimum \\
\hline \multicolumn{6}{|l|}{ Extent to which patient dumping has occurred } \\
\hline Very serious & $13(5.2)$ & & & & \\
\hline Serious & $62(24.7)$ & & & & \\
\hline Average & $78(31.1)$ & & & & \\
\hline Not serious & $45(17.9)$ & & & & \\
\hline Not at all & $13(5.2)$ & & & & \\
\hline Do not know & $40(15.9)$ & & & & \\
\hline \multicolumn{6}{|c|}{ Percentage of hospitals engaging in patient dumping } \\
\hline Those who did not answer this question & $61(24.3)$ & 13.47 & 16.63 & 80.0 & 0.0 \\
\hline Those who did answer this question & $190(75.7)$ & & & & \\
\hline \multicolumn{6}{|c|}{ Percentage of emergency patients received by transfer from other hospitals } \\
\hline Those who did not answer this question & $37(14.7)$ & 5.91 & 8.10 & 50.0 & 0.0 \\
\hline Those who did answer this question & $214(85.3)$ & & & & \\
\hline \multicolumn{6}{|c|}{ Percentage of inpatients received by transfer from other hospitals } \\
\hline Those who did not answer this question & $43(17.1)$ & 5.62 & 7.34 & 50.0 & 0.0 \\
\hline Those who did answer this question & $208(82.9)$ & & & & \\
\hline
\end{tabular}

a Total sample number $=251$.

superintendents' perceived extent of patient dumping within their healthcare network and the factors potentially contributing to such patient dumping. The analysis reveals that after controlling for other factors, the superintendents' perceived extent of the patient dumping occurring within their healthcare networks was positively related to (i) the total number of patients covered under the case payment system $(\mathrm{OR}=1.00$, 95\% CI $=1.00-1.00, p=0.006$ ); (ii) the total number of discharged patients $(\mathrm{OR}=1.00,95 \% \mathrm{CI}=1.00-1.00$, $p=0.001$; (iii) the extent of healthcare market competition $(\mathrm{OR}=4.86,95 \% \mathrm{CI}=2.26-10.46, p<0.001)$; (iv) the number of respondent's hospital beds $(\mathrm{OR}=1.00$, 95\% CI $=1.00-1.01, p=0.009$ ). There was, however, no significant relationship between the superintendents' perceived extent of patient dumping occurring within their healthcare network and their hospital ownership or level.

\section{Discussion}

The national survey undertaken by this study was aimed at exploring the prevalence of patient dumping in Taiwan and the factors contributing to its occurrence. Despite the fact that very few studies have ever mentioned this issue, we found that patient dumping in Taiwan is indeed a widespread problem. As Table 2 shows, of the total of 211 respondents to the survey, 198 (93.8\%) felt that, irrespective of their hospital level, ownership or teaching status, some degree of patient dumping was occurring within their service areas, with the overall responses ranging from 'not serious' to 'very serious'.

We found that respondents perceived that different percentages of hospitals $($ mean $=13.47 \%)$ transferred patients solely on economic considerations in their service areas (Table 2). The mean percentage found in this study is much lower than the $64.7 \%$ found in the study of community mental health centers in the US conducted by Schlesinger et al. [3]; nevertheless, it is very close to the finding of a mean of $13 \%$ in a parallel study conducted on 1363 US hospital CEOs in 1992 [12], and also gains support from the fact that about 1 in 10 acute care hospitals throughout the US have actually been caught in violation of anti-dumping statutes [13].

It also came as no surprise to find that more than $40 \%$ of the superintendents sampled in this study indicated that the financial integrity of their hospitals was currently being severely impaired by patient dumping (Table 3).

According to the US experience of patient dumping, as reported by Schiff et al., the annual cost to those hos- 
Table 3

Attitudes towards patient dumping ${ }^{\mathrm{a}}$

\begin{tabular}{|c|c|}
\hline Variable & Total no. $(\%)$ \\
\hline \multicolumn{2}{|c|}{ Financial impact of patient dumping on hospitals } \\
\hline Positive & $26(10.4)$ \\
\hline Negative & $101(40.2)$ \\
\hline No impact & $81(32.3)$ \\
\hline Do not know & $43(17.1)$ \\
\hline \multicolumn{2}{|c|}{ Type of hospital associated with patient dumping } \\
\hline Public & $25(10.0)$ \\
\hline Private not-for-profit & $67(26.7)$ \\
\hline Private for-profit & $94(37.5)$ \\
\hline Do not know & $65(25.9)$ \\
\hline \multicolumn{2}{|c|}{ Type of hospital associated with patient dumping } \\
\hline Teaching & $77(30.7)$ \\
\hline Non-teaching & $79(31.1)$ \\
\hline Do not know & $96(38.2)$ \\
\hline \multicolumn{2}{|c|}{ Case payment has increased patient dumping } \\
\hline Strongly agree & $28(11.2)$ \\
\hline Agree & $93(37.1)$ \\
\hline No strong opinion & $46(18.3)$ \\
\hline Disagree & $58(23.1)$ \\
\hline Strongly disagree & $14(5.6)$ \\
\hline Do not know & $12(4.8)$ \\
\hline \multicolumn{2}{|c|}{ Global budget system has increased patient dumping } \\
\hline Strongly agree & $87(34.7)$ \\
\hline Agree & $126(50.2)$ \\
\hline No strong opinion & $20(8.0)$ \\
\hline Disagree & $10(4.0)$ \\
\hline Strongly disagree & $2(0.8)$ \\
\hline Do not know & $6(2.4)$ \\
\hline \multicolumn{2}{|c|}{ Patient dumping increases mortality rates } \\
\hline Strongly agree & $44(17.5)$ \\
\hline Agree & $123(49.0)$ \\
\hline No strong opinion & $32(12.7)$ \\
\hline Disagree & $33(13.1)$ \\
\hline Strongly disagree & $5(2.0)$ \\
\hline Do not know & $15(5.6)$ \\
\hline \multicolumn{2}{|c|}{ Patient dumping increases consumption of medical resources } \\
\hline Strongly agree & $31(12.4)$ \\
\hline Agree & $112(44.6)$ \\
\hline No strong opinion & $45(17.9)$ \\
\hline Disagree & $49(19.5)$ \\
\hline Strongly disagree & $4(1.6)$ \\
\hline Do not know & $10(4.0)$ \\
\hline
\end{tabular}

a Total sample number $=251$.

pitals receiving patients dumped from other hospitals ran into millions of US dollars [2]. Ansell and Schiff estimated that the total cost per annum to public hospitals in the US, as a direct result of patient dumping, was approximately US\$ 1.04 billion [11], while Bernard et al. also indicated that those patients that had been dumped often consumed more hospital resources than other patients because of the delay in their treatment or the high severity of their illnesses [14]. This concurs with our finding of approximately $57 \%$ of respondents agreeing that patient dumping led to increased consumption of medical resources (Table 3). It follows, therefore, that a solution to the problem of patient dumping in Taiwan could well prove to be an important factor in helping to resolve the corresponding problem of escalating medical expenditure within the island's NHI system.

With regard to the impact of patient dumping on the overall health of patients, this study has found that $66.5 \%$ of respondents 'agreed' or 'totally agreed' that patient dumping would result in increased mortality rates (Table 3). This is consistent with the conclusions of another study, which found that the well being of $32 \%$ of transferred patients was jeopardized by their transfer [15]. An additional noteworthy report submitted to a Congressional subcommittee by Ansell and Schiff noted that almost 1 in 10 dumped patients died in the receiving hospitals [11]. Clearly, therefore, in terms of overall patient health, patient dumping is a very serious problem, since a delay in treatment resulting from patient dumping obviously endangers the lives of those patients requiring immediate attention.

This study has shown that the majority of the sampled superintendents felt that the transfer of patients based upon economic considerations was most likely to occur in private FP hospitals. This observation is consistent with the empirical findings of Schlesinger et al., who reported that the transfer of patients on economic grounds was most likely to be undertaken by FP community mental health centers [3].

However, the statistical analysis undertaken in this study has failed to uncover any significant relationship between the respondents' perceived extent of patient dumping occurring within their respective healthcare networks and the percentage of beds in FP hospitals (vis-à-vis the total number of hospital beds). This finding runs contrary to the empirical studies of Relman [9] and Hurley et al. [16] in the US, both of which found that patient dumping was more prevalent in regions characterized by a greater proportion of private FP hospitals.

One possible reason for such inconsistency is that under Taiwan's NHI, there may have been some con- 
Table 4

Relationship between perceived extent of patient dumping and possible contributory factors ${ }^{\mathrm{a}}$

\begin{tabular}{|c|c|c|c|c|c|c|c|}
\hline \multirow[t]{3}{*}{ Variable } & \multicolumn{6}{|c|}{ Perceived extent } & \multirow[t]{3}{*}{$p$-Value } \\
\hline & \multicolumn{3}{|l|}{ Serious } & \multicolumn{3}{|c|}{ Not serious } & \\
\hline & Mean & S.D. & Total no. $(\%)$ & Mean & S.D. & Total no. $(\%)$ & \\
\hline Patients covered by case payment scheme & 73348 & 39149 & - & 45597 & 35878 & - & $<0.001$ \\
\hline Number of hospitals & 58 & 27 & - & 49 & 34 & - & 0.001 \\
\hline Number of discharged patients & 405101 & 200531 & - & 265954 & 191543 & - & $<0.001$ \\
\hline Number of beds & 16312 & 8693 & - & 10549 & 7772 & - & $<0.001$ \\
\hline Hospitalized patients transferred to other hospitals & 4533 & 1500 & - & 3607 & 2020 & - & $<0.001$ \\
\hline Percentage of beds in public hospitals to total beds & 0.33 & 14 & - & 0.36 & 14 & - & 0.073 \\
\hline Percentage of beds in private FP hospitals to total beds & 0.29 & 15 & - & 0.27 & 15 & - & 0.683 \\
\hline Percentage of beds in teaching hospitals to total beds & 0.81 & 9 & - & 0.75 & 12 & - & $<0.001$ \\
\hline \multicolumn{8}{|l|}{ Extent of healthcare market competition } \\
\hline Competitive & - & - & $50(67)^{\mathrm{c}}$ & - & - & $29(21)$ & - \\
\hline Moderately competitive & - & - & $25(33)$ & - & - & $74(54)$ & - \\
\hline Not competitive & - & - & - & - & - & $33(25)$ & - \\
\hline
\end{tabular}

a Total sample number $=211$.

${ }^{\mathrm{b}} p$-Values are calculated by $t$-test.

c $p$-Values cannot be calculated since one cell is zero.

Table 5

Logistic regression results on factors relating to the extent of patient dumping ${ }^{\mathrm{a}}$

\begin{tabular}{|c|c|c|c|}
\hline Variable & Odds ratio & $95 \% \mathrm{CI}$ & $p$-Value \\
\hline Patients covered by case payment scheme & 1.00 & $1.00-1.00$ & 0.006 \\
\hline Number of hospitals & 0.96 & $0.92-1.01$ & 0.066 \\
\hline Number of discharged patients & 1.00 & $1.00-1.00$ & 0.001 \\
\hline Number of beds & 0.99 & $0.99-1.00$ & 0.130 \\
\hline Hospitalized patients transferred to other hospitals & 0.98 & $0.98-1.01$ & 0.153 \\
\hline Percentage of beds in teaching hospitals to total beds & 0.25 & $0.01-20.75$ & 0.539 \\
\hline \multicolumn{4}{|l|}{ Extent of healthcare market competition } \\
\hline Competitive (yes/no) & 4.86 & $2.26-10.46$ & 0.000 \\
\hline Moderately competitive (reference group) & - & - & - \\
\hline Number of respondent's hospital beds & 1.00 & $1.00-1.01$ & 0.009 \\
\hline \multicolumn{4}{|l|}{ Hospital level } \\
\hline Medical center (yes/no) & 0.37 & $0.03-4.77$ & 0.445 \\
\hline Regional hospital (yes/no) & 2.19 & $0.62-7.75$ & 0.225 \\
\hline District teaching hospital (yes/no) & 1.10 & $0.34-3.51$ & 0.874 \\
\hline District non-teaching hospital (reference group) & - & - & - \\
\hline \multicolumn{4}{|l|}{ Hospital ownership } \\
\hline Public (yes/no) & 0.75 & $0.27-2.10$ & 0.580 \\
\hline Private not-for-profit (yes/no) & 1.41 & $0.42-4.71$ & 0.574 \\
\hline Private for-profit (reference group) & - & - & - \\
\hline
\end{tabular}

\footnotetext{
a Total sample number $=211$.
} 
siderable convergence in the different behaviors of hospitals under different ownership [17]. Although many public and NFP hospitals may formerly have been unaccustomed to economic pressures, due to the constraints of government budgets, the need for solicitation of charitable contributions from philanthropists, and the intensive competition in the healthcare market, the likelihood is that they may eventually have been impelled to selectively admit low-cost or profitable patients and to discourage the admission of high-cost or unprofitable patients in order to maintain acceptable profit levels.

This study has shown that the level of market competition is another important factor helping to explain the extent of patient dumping within the healthcare market. This finding is in line with the study by Schlesinger et al., which found that increasing competition between hospitals in the US might well have aggravated the practice of economically motivated transfers [3]. This also supports the argument pursued by Weissman that the spread of market competition is one of the three trends influencing the reported frequency and intensity of patient dumping [10].

Hospitals located in areas with greater competition tend to provide better services in order to attract, or keep, 'financially attractive' patients. Arguably, this strategy may lead to an increase in the total costs of care provision, thereby placing hospitals under greater financial pressure. Many empirical studies in the US and Taiwan have also consistently demonstrated higher costs in the more competitive healthcare markets $[17,18]$, largely because lower profit margins accompanied by higher costs in the more competitive markets will tend to place considerable strains on the willingness of hospitals to admit 'financially unattractive' patients.

This study has revealed a significant relationship between the number of patients for whom payment is made under the case payment system and the respondents' perceived extent of patient dumping within their healthcare market. This finding also concurs with the results of the study by Weissman, which found that incidences of patient dumping were related to the implementation of a prospective payment system in the US [10].

The BNHI in Taiwan initiated a case payment system alongside the introduction of the NHI in 1995. Under this system, hospitals are paid a fixed amount for each patient treated based upon either the principal discharge diagnosis or the principal operative procedure, rather than on the actual costs of the inpatient resources consumed. The case payment system results in hospitals keeping (or absorbing) any differentials between their costs and the established rate for the provision of patient care. Therefore, the case payment system may well create financial incentives for hospitals to selectively admit profitable patients and to transfer more complex and unprofitable patients.

Similar to the responses on the impact of the case payment system on patient dumping, about $85 \%$ of respondents agreed that the implementation of the global budget system had also led to increased occurrences of patient dumping; this is supported by the observations of Lin et al., who found that the introduction of a hospital global budget system may have exacerbated the problem of patient dumping within Taiwan [19].

Under the hospital global budget system in Taiwan, all hospitals now share a predetermined and fixed total amount (expenditure cap) of all the healthcare service provisions for patients. The introduction of this system may, however, have created financial incentives for hospitals to discourage the admission of patients with illnesses of greater severity. Nevertheless, there is, as yet, scant information on the dynamics, the magnitude or the impacts of the global budget system on patient dumping. Further research will, therefore, be necessary in order to explore the extent to which patient dumping can be linked to the implementation of a global budget system.

\section{Conclusions}

Before presenting our conclusions, we must refer to two obvious limitations of this study. First of all, despite a clear definition of patient dumping having been provided at the beginning of the questionnaire, some hospital superintendents were unfamiliar with the issues relating to patient dumping. Consequently, about $16 \%$ of the respondents were ill equipped to answer questions pertaining to the extent of patient dumping within their service areas. Secondly, although the survey for this study was carried out at the end of 2004, there was no other option available to us but to use the NHIRD for the year 2003 to calculate the total num- 
ber of discharges and the total number of hospitalized patients being transferred, simply because the NHIRD for the year 2004 has not yet been released.

Despite these limitations, this study concludes that patient dumping is a widespread problem in the healthcare industry in Taiwan under the NHI system, and that the implementation of the case payment and global budget systems within the island's hospitals may even have aggravated the problem. Nevertheless, very few studies have so far attempted to address the issues relating to patient dumping in other countries outside of the US. Moreover, the major focus of most of the US literature on patient dumping has tended to be placed on the transfer of uninsured patients. It is, therefore, recommended that a well-designed survey be undertaken to investigate the prevalence of patient dumping occur- ring in countries which either have, or are currently contemplating the design and introduction of, a similar healthcare system or reimbursement mechanism.

This study further concludes that a significant relationship exists between the extent of patient dumping and the level of market competition, the number of patients covered under the prospective payment system, and the total number of discharged patients within a given healthcare market segment. This finding can help policymakers in Taiwan, as well as in other countries with similar healthcare systems, to identify those healthcare markets in which patients are more likely to be transferred for economic reasons. Other countries may also find our study results helpful when investigating this topic, since they should prove useful in terms of facilitating cross-country comparisons.

\section{Appendix A. Questionnaire on perceptions of patient dumping}

\begin{tabular}{|c|c|}
\hline Questions & Responses \\
\hline \multicolumn{2}{|l|}{ Part 1} \\
\hline $\begin{array}{l}\text { 1. Extent to which patient dumping has occurred in your healthcare } \\
\text { network }\end{array}$ & $\begin{array}{l}\text { Very serious, serious, average, not serious, not at all, do } \\
\text { not know }\end{array}$ \\
\hline \multicolumn{2}{|l|}{$\begin{array}{l}\text { 2. Percentage of hospitals engaging in patient dumping in your } \\
\text { healthcare network }\end{array}$} \\
\hline \multicolumn{2}{|l|}{$\begin{array}{l}\text { 3. Percentage of emergency patients received by transfer from other } \\
\text { hospitals }\end{array}$} \\
\hline \multicolumn{2}{|l|}{ 4. Percentage of inpatients received by transfer from other hospitals } \\
\hline \multicolumn{2}{|l|}{ Part 2} \\
\hline 1. Financial impact of patient dumping on respondent's hospital & Positive, negative, no impact, do not know \\
\hline 2. Which type of hospitals are more likely to practice patient dumping & Public, private NFP, private FP, do not know \\
\hline 3. Which type of hospitals are more likely to practice patient dumping & Teaching, non-teaching, do not know \\
\hline 4. Extent of competition which occurred in your healthcare network & $\begin{array}{l}\text { Very competitive, moderately competitive, not competi- } \\
\text { tive, do not know }\end{array}$ \\
\hline 5. Case payment has increased patient dumping & $\begin{array}{l}\text { Strongly agree, agree, agree somewhat, disagree, strongly } \\
\text { disagree }\end{array}$ \\
\hline 6. Global budget has increased patient dumping & Same as above \\
\hline 7. Patient dumping increases mortality rates & Same as above \\
\hline 8. Patient dumping increases consumption of medical resources & Same as above \\
\hline \multicolumn{2}{|l|}{ Part 3} \\
\hline 1. Healthcare network where hospital is located & $\begin{array}{l}\text { Keelung, Taipei, Taoyuan, Hsinchu, Miaoli, Taichung, } \\
\text { Changhua, Nantou, Yunlin, Chiayi, Tainan, Kaohsiung, } \\
\text { Pingtung, Taitung, Hualien, Ilan, Penghu }\end{array}$ \\
\hline 2. Respondent's hospital ownership & Public, private NFP, private FP \\
\hline 3. Respondent's hospital level & Medical center, regional hospital, district hospital \\
\hline 4. Total number of beds in respondent's hospital & - \\
\hline
\end{tabular}




\section{References}

[1] Alwyn C. Financial considerations provoked patient dumping, activist charges. American Hospital Association News 1997;33:49.

[2] Schiff RL, Ansell DA, Schlosser JE, Idris AH, Morrison A, Whitman S. Transfers to a public hospital. A prospective study of 467 patients. The New England Journal of Medicine 1986;314:552-7.

[3] Schlesinger M, Dorwart R, Hoover C, Epstein S. The determinants of dumping: a national study of economically motivated transfers involving mental health care. Health Services Research 1997;32:561-90.

[4] Hylton MO. The economics and politics of emergency health care for the poor: the patient dumping dilemma. Bright Young University Law Review 1992;1992:971-1033.

[5] Higginbotham EL. Patient-dumping cases still pose a problem. RN 1999;62:63-5.

[6] Silverman J. Consumer report spotlights patient "dumping". OB/GYN News, 1 September 2001.

[7] Lin HC, Yang MC, Chen CC, Tang CH. Hospital administrators' opinions toward the prevalence of patient dumping in Taiwan. Chang Gung Medical Journal (Taiwan) 2004;27:35-43.

[8] Berliner HS. Patient dumping-no one wins and we all lose. American Journal of Public Health 1988;78:1279-80.

[9] Relman AS. Texas eliminates dumping. A start toward equity in hospital care. The New England Journal of Medicine 1986;314:578-9.

[10] Weissman JS. Commentary: economic transfers, the changing face of a familiar problem. Health Services Research 1997;32:591-8.
[11] Ansell DA, Schiff RL. Patient dumping. Status, implications, and policy recommendations. The Journal of the American Medical Association 1987;257:1500-2.

[12] Pollarito K. Patient dumping occurring, say $13 \%$ of CEOs. Modern Healthcare 1992;22:24.

[13] Anonymous. Hospital emergency rooms and patient dumping. Health Letters 1998;17:1-3.

[14] Bernard AM, Hayward RA, Rosevear J, Chun H, McMahon LF. Comparing the hospitalizations of transfer and non-transfer patients in an academic medical center. Academic Medicine 1996;71:262-6.

[15] Himmelstein DU, Woolhandler S, Harnly M, et al. Patient transfers: medical practice as social triage. American Journal of Public Health 1984;74:494-7.

[16] Hurley J, Linz D, Swint E. Assessing the effects of the Medicare Prospective Payment System on the demand for VA inpatient services: an examination of transfers and discharges of problem patients. Health Services Research 1990;25(1 Pt 2):23955.

[17] Xirasagar S, Lin HC. Cost convergence between public and for-profit hospitals under prospective payment and high competition in Taiwan. Health Services Research 2004;39(6 Pt 2):2101-16.

[18] Hadley J, Swartz K. The impacts on hospital costs between 1980 and 1984 of hospital rate regulation, competition, and changes in health insurance coverage. Inquiry 1989;26:3547.

[19] Lin HC, Yang CH, Tung YC, Chang WY. Comparing costs and hospital ownership for thyroidectomy patients. New Taipei Journal of Medicine 2002;4:34-43. 